\title{
Integrating the Health of Socially Vulnerable Populations into Residency Programs
}

Luke A. Rannelli MD MSc, Karen Tang MD, Rahim Kachra MD, Janeve Desy MD, Gabriel Fabreau MD MPH

DOI: $10.22374 /$ cjgim.v13i1.225

\section{About the Authors}

Luke A. Rannelli, Karen Tang, Rahim Kachra, Janeve Desy, and Gabriel Fabreau are with the Faculty of Medicine, University of Calgary, Calgary, Alberta, Canada. Gabriel Fabreau is also with the Faculty of Community Health Sciences, University of Calgary.

Correspondence can be directed to: larannel@ucalgary.ca

Submitted: July 12, 2017. Accepted: October 15, 2017 Published: March 5, 2018.

\begin{abstract}
In Canada, growing disparities in health disproportionally affect socially vulnerable populations. The Royal College of Physician and Surgeons of Canada has attempted to incorporate health equity for socially vulnerable populations within the competency training objectives set forth for internal medicine (IM) residents. However, trainee exposure to these populations beyond inpatient contact in tertiary care hospitals has not traditionally been a requirement of IM training. At the University of Calgary, we have developed a four-week clinical rotation that aims to expose residents to social determinants for socially vulnerable populations.

To our knowledge this is the first clinical rotation within an IM program in Canada dedicated to exposing and educating residents on the broader care of socially vulnerable populations. Our goal is to train internists and subspecialists to gain the empathy, skills, and knowledge to better provide care for socially vulnerable populations and to advocate for health equity, throughout their careers.
\end{abstract}

\section{Résumé}

Au Canada, les disparités grandissantes en santé touchent de façon disproportionnée les populations socialement vulnérables. Le Collège royal des médecins et chirurgiens du Canada tente d'intégrer l'équité en santé chez les populations socialement vulnérables à l'intérieur des objectifs de formation des compétences des résidents en médecine interne (MI). Toutefois, l'exposition des apprenants à ces populations au-delà des contacts avec les patients hospitalisés dans les hôpitaux de soins tertiaires n'est habituellement pas une exigence dans la formation en MI. À l'Université de Calgary, un stage clinique de quatre semaines a été élaboré afin d'exposer les résidents aux déterminants sociaux de populations socialement vulnérables.

À notre connaissance, il s'agit du premier stage clinique intégré à un programme de $\mathrm{MI}$ au Canada visant à exposer et à sensibiliser les résidents aux soins étendus chez les populations socialement vulnérables. Le but de ce stage consiste à entrainer les internistes et les surspécialistes à développer l'empathie, les compétences et les connaissances qui permettent de mieux traiter les populations socialement vulnérables et de prendre position en faveur de l'équité en matière de santé tout au long de leur carrière. 


\section{Unique Challenges in the Health of Vulnerable Populations}

In Canada, growing disparities in health disproportionally affect socially vulnerable populations. ${ }^{1-5}$ While the majority of Canadians benefit from timely and high-quality care, some Canadians are still left behind. ${ }^{6-9}$

Accurately defining socially vulnerable populations can be difficult. We have adopted Mechanic \& Tanner's definition of socially vulnerable populations as groups of individuals that share susceptibility to harm as a result of economic arrangements, social status, inadequate community support systems and interpersonal networks. ${ }^{10}$ In Canada, examples of socially vulnerable populations include Indigenous Canadians, ${ }^{11}$ lowincome individuals, those experiencing housing and/or food insecurity, ${ }^{12}$ members of the lesbian gay bisexual transgendered queer (LGBTQ) community ${ }^{12,13}$ and many new immigrants and refugees to Canada. ${ }^{14}$ These populations tend to be medically complex ${ }^{1-5}$ and present to acute care more often than individuals from the general population. ${ }^{15-18}$ Health disparities, therefore, have important implications for provincial health expenditures as socially vulnerable populations tend to require more hospital resources and have higher health care costs. ${ }^{16-18}$

Despite their increased medical complexity, adherence to medical therapy is often compromised, as individuals from socially vulnerable groups must often prioritize food and basic needs over costly medications. ${ }^{5,19,20}$ Higher rates of mental illness and substance abuse further increase the socially vulnerable patient's risk of adverse health outcomes ${ }^{19-22}$ Ultimately, individuals from socially vulnerable groups will have considerably higher overall morbidity and lower life expectancy compared to the general population. ${ }^{3,15}$ Given these challenges, health care providers must identify and address the underlying social determinants of health in addition to medical and psychosocial issues to provide high-quality care to socially vulnerable individuals.

\section{Current Status of Medical Education Specific to Health of Vulnerable Populations}

The Royal College of Physician and Surgeons of Canada has incorporated health equity for socially vulnerable populations within the competency training objectives set forth for internal medicine (IM) residents. Specifically, IM residents should be able to define and identify the determinants of health for the populations they serve. This includes identifying barriers to accessing health care for socially vulnerable populations, as well as advocating for change that addresses the social determinants of health ${ }^{23}$ in the communities they serve. Although exposure to these populations is inherent in a resident's clinical training on the general medical wards, explicit teaching regarding the social determinants of health and their role in the medical care of socially vulnerable patients is often overlooked ${ }^{24,25}$ Specific competency within the Royal College objectives of training in providing care to vulnerable populations has not been well characterized. Furthermore, trainee exposure to these populations beyond that in tertiary care hospitals has not traditionally been a requirement of IM training. In Canada, the education, exposure and assessment of residents' training with socially vulnerable populations are the responsibility of individual residency training programs. ${ }^{23}$

A survey of IM training programs in the United States in 2008 determined that only $10-30 \%$ of schools had dedicated curricular components focusing on ethnic minority, LGBTQ and non-English speaking patients. Residents recognize these deficiencies in training, with the majority of trainees expressing inadequate knowledge of vulnerable population health and indicating that more formal training in these areas should be built into residency training. ${ }^{26}$ Furthermore, numerous studies evaluating medical students have consistently shown a decline in empathy and attitudes towards marginalized populations throughout the course of their training. ${ }^{27-29}$ This may result from a combination of complex factors. The lack of structured clinical exposures provided by positive senior role models has been postulated to be a significant contributor to this decline..$^{25,29}$ Within residency programs, trainees often cite illdefined objectives, absence of a structured curriculum, and lack of modelled behaviour as barriers in their education around health advocacy. ${ }^{29}$ Providing physicians-in-training with positive mentors and structured learning environments within the socially vulnerable communities may therefore increase their empathy and awareness of the unique challenges faced when caring for socially vulnerable patients. ${ }^{30,31}$

Programs such as "Making the Links" at the University of Saskatchewan have been used as examples of positive structured, service-based learning program focused on marginalized populations. $^{32}$ Through structured medical encounters and recruitment of physicians trained within these areas, medical students gain a better understanding of medical care in socially vulnerable populations. This program, like many others, is limited to the undergraduate medical education level without similar options for postgraduate trainees. In Canada, select IM training programs have incorporated care of socially vulnerable populations into their didactic academic curriculum with some also offering additional medical clinics in underserved populations and refugee health. However, in an informal survey of 12 programs across the country, only the University of Toronto has a dedicated rotation designed to provide residents with exposures to the social determinants of health through dedicated advocacy teaching rounds and opportunities for trainees to be exposed to local community resources such as homeless shelters. ${ }^{33}$ The lack 
of dedicated training within vulnerable populations health is not unique to Canada; a systematized review of health disparities training at the residency level identified only 15 programs in the United States that had a focused longitudinal or block education experiences for trainees. ${ }^{34}$

In the United States, IM residency training programs that focus on integration of care for socially vulnerable populations into residency education ${ }^{30,31}$ have developed a dedicated third-year residency track or block experience that includes didactic teaching sessions; inpatient service and ambulatory care experiences. ${ }^{31,34}$ Residents who participated in these programs were more likely to have higher job satisfaction, were better prepared as clinic managers, and were more likely to choose to specialize in general internal medicine (GIM) ${ }^{30,31}$ Most importantly, patient care outcomes in these programs were superior to many national health metrics for similarly marginalized populations. ${ }^{30,31}$

In Canada, an integrated clinical education approach to vulnerable population health is not a new concept to our colleagues in family practice. ${ }^{35-37}$ Focused primary care medicine training in marginalized populations has demonstrated high resident satisfaction, improved culturally appropriate care of underserved populations, and trainees better prepared for independent practice. ${ }^{38,39}$ These positive experiences lead to improved retention of primary care physicians to underserviced settings. ${ }^{38,39}$ Pediatric medical education has also integrated clinical rotations into residency programs that exposes learners to a variety of medical and non-medical community based organizations that serve local vulnerable populations. This has shown an increase in resident's comfort and competency with medical practice in underserved patients. ${ }^{40-42}$

Therefore, the development of structured clinical servicebased learning opportunities supported by preceptors wellversed in this area of practice can improve not only residents' understanding of the impact of the social determinants of health on socially vulnerable populations, but more importantly may also lead to improved patient care.

\section{The Calgary Experience}

At the University of Calgary, we have developed a four-week clinical rotation that exposes residents to a variety of clinical and non-clinical experiences in primary care, subspecialty medical clinics, harm reduction programs, emergency shelters, social work and community outreach programs that provide care for socially vulnerable groups in Calgary. Through this rotation we aim to train physicians to address the social determinants of health and the barriers faced by socially vulnerable populations in their daily practice.

The Health of Vulnerable Populations Selective is a four-week clinical rotation offered to second and third-year IM residents at the University of Calgary that was initially created in 2010. The original design of the rotation included clinical care opportunities at various medical clinics such as human immunodeficiency virus (HIV) health, tuberculosis care and diabetic management in lowincome individuals in the Calgary area. In an effort to provide a more broad-based exposure to social, economic and health problems involved in the care of socially vulnerable populations, the elective was expanded in 2015 to also include non-clinical experiences. We have additionally identified five critical areas of focus for resident exposure that include urban/inner city health, refugee/immigrant care, LBGTQ health, Indigenous health and low-income/senior care. Residents are encouraged to dedicate half of their rotation time in medical clinics and the remainder of their time in non-medical organizations/agencies.

Medical clinics available to residents include inner city and urban health GIM clinics, Indigenous health GIM and rheumatology clinics, HIV and tuberculosis treatment clinics, refugee health clinics, geriatric low-income assessments, and low-income/new Canadians endocrinology consultations. Nonmedical exposures include harm reduction programs such as needle exchange, opioid dependence treatment programs, and alcohol detoxification centres. Furthermore, mobile community health outreach and low-income/homeless shelter response teams allow residents exposure to homeless shelters/community

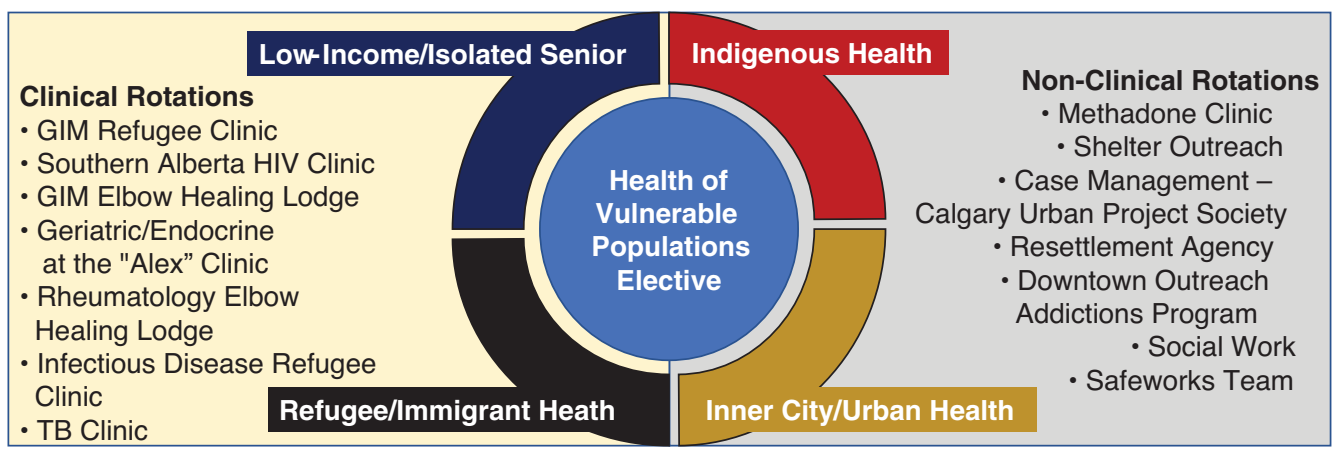

Figure 1 
housing resources. Residents can also explore social community resources through social work services at dedicated Indigenous, inner city and LGBTQ health clinics. This combination of clinical and non-clinical experiences provides IM residents with extensive opportunities to learn from various health care providers, not limited to physicians within internal medicine and its subspecialties. Rotation preceptors include physicians, nurses, social workers and community outreach workers experienced in providing care to underserved populations. Residents who complete this elective are also provided with a list of journal articles and resources to facilitate self-directed learning about the social determinants of health and the health of socially vulnerable populations.

Traditional evaluation is implemented in this rotation through in-training evaluation reports to assess residents' clinical performance and ability to provide quality patient care in the ambulatory setting. This is complemented by a self-reflection or clinical prescription assignment, which has been shown to reduce trainee bias towards vulnerable populations. ${ }^{43}$ Additionally, we encourage residents to integrate research and advocacy projects to further enhance their understanding of the field, though this advanced work is not mandatory. Previous projects that have been completed by residents have included literature reviews, research proposals, and personal reflective papers on their experiences from this selective.

\section{The Future}

This Health of Vulnerable Populations Selective underwent significant revision in 2015 in order to broaden trainees' exposures to the different aspects of the social determinants of health and gain a deeper understanding of the socially vulnerable patients they serve. Moving forward, we envision an expansion beyond the core IM program to include the subspecialty GIM program.
Given the complex and dynamic nature of studying an educational program with our concurrent plan to redesign and improve implementation, we will use the context/input/ process/product model of medical curriculum evaluation ${ }^{44}$ We will continuously seek to redesign and improve program implementation in an iterative fashion. ${ }^{44}$ Beginning in 2017 the context evaluation will begin through solicited surveys and demographic data analysis of residents' and preceptors' perceived knowledge and deficiencies of providing care to socially vulnerable populations. Input evaluation will occur through solicited feedback on the rotation design from our program stakeholders including our community partners, clinic workers and support personnel. After these consultations are completed, implementation of the re-designed program will begin with participant interview feedback sessions from rotation residents, preceptors and stake holders in an effort to complete a process evaluation. Finally, product evaluation will include assessments of residents' knowledge and comfort with topics involved in the care of vulnerable populations using surveys conducted pre-rotation and 1-year post rotation.

\section{Conclusion}

At the University of Calgary, we have developed a unique fourweek subspecialty rotation aimed at providing our residents with a broad exposure to the complex aspects involved in the care of socially vulnerable patients. Ultimately, we aim to train internists and subspecialists to gain the empathy, skills, and knowledge to better provide care for socially vulnerable populations and to advocate for health equity throughout their careers.

\section{Acknowledgements}

The authors would like to acknowledge the University of Calgary IM program, as well as the current and former program director

\begin{tabular}{|l|l|l|l|l|l|l|l|}
\hline & Sunday & \multicolumn{1}{|c|}{ Monday } & Tuesday & Wednesday & Thursday & \multicolumn{1}{|c|}{ Friday } & \multicolumn{1}{|l|}{ Saturrday } \\
\hline AM & CTU Coverage & Tuberculosis Clinic & HIV Clinic & $\begin{array}{l}\text { Sheldon } \\
\text { Chumir Social } \\
\text { Work }\end{array}$ & $\begin{array}{l}\text { GIM - Morley } \\
\text { Reserve Clinic }\end{array}$ & $\begin{array}{l}\text { GIM - Refugee } \\
\text { Clinic }\end{array}$ & \\
\hline PM & CTU Coverage & $\begin{array}{l}\text { GIM Elbow } \\
\text { Healing Lodge }\end{array}$ & $\begin{array}{l}\text { Safeworks Mobile } \\
\text { Unit }\end{array}$ & $\begin{array}{l}\text { Academic } \\
\text { Half-day }\end{array}$ & $\begin{array}{l}\text { GIM - Morley } \\
\text { Reserve Clinic }\end{array}$ & $\begin{array}{l}\text { Infectious } \\
\text { Disease - } \\
\text { Refugee Clinic }\end{array}$ & \\
\hline NIGHT & & & & & $\begin{array}{l}\text { DOAP } \\
\text { Transport }\end{array}$ & \\
\hline
\end{tabular}

Figure 2 
under which the program was developed, Drs Marcy Mintz, Michael Fisher, and Jeffrey Schaefer. We would also like to recognize the clinical preceptors, social workers, community health workers and organizations that permit resident participation and foster their education. Thank you to the Calgary Urban Project Society, Alpha House Calgary, Safeworks, Downtown Outreach Addictions Program, Elbow Healing Lodge and Calgary Refugee Health Clinic for their contributions to the program.

\section{Author's Contribution}

LAR wrote the manuscript; RK, JD, KT \& GF contributed to discussion, reviewed/edited manuscript; LAR and GF take responsibility for the contents of the article

\section{Competing Interest}

The authors declare that they have no competing interests. Furthermore, we have no financial competing interests.

\section{References}

1. Goel V. Socioeconomic status and cancer incidence and survival. Cancer Prev Control 1998;2(5):211-2.

2. Choinière R, Lafontaine P, Edwards AC. Distribution of cardiovascular disease risk factors by socioeconomic status among Canadian adults. CMAJ 2000;162(9 Suppl):S13-24.

3. Hwang SW, Wilkins R, Tjepkema M, O'Campo PJ, Dunn JR. Mortality among residents of shelters, rooming houses, and hotels in Canada: 11 year follow-up study. BMJ 2009;339:b4036.

4. Frohlich KL, Potvin L. Transcending the known in public health practice: the inequality paradox: the population approach and vulnerable populations. Am J Public Health 2008;98(2):216-21.

5. Tarasuk V, Cheng J, de Oliveira C, Dachner N, Gundersen C, Kurdyak P. Association between household food insecurity and annual health care costs. CMAJ 2015;187(14):E429-36.

6. Dunn JR. Are widening income inequalities making Canada less healthy? 2002. Available at: http://en.healthnexus.ca/sites/en.healthnexus.ca/files/ resources/widening_income_equalities.pdf.

7. Bierman A, Shack A, Johns A. Achieving health equity in Ontario: Opportunities for intervention and improvement. Toronto; 2012.

8. Murphy K, Glazier R, Wang X, Holton E, Fazli G, Ho M. Hospital care for all: An equity report on di erences in household income among patients at Toronto Central Local Health Integration Network (TC LHIN) hospitals. Toronto, Ontario; 2012.

9. Canadian Medical Association. CMA position statement: Ensuring equitable access to care: Strategies for governments, health system planners, and the medical profession. Ottawa Ontario: Canadian Medical Association; 2013.

10. Mechanic D, Tanner J. Vulnerable people, groups, and populations: Societal view. 2007.

11. MacMillan HL, MacMillan AB, Offord DR, Dingle JL. Aboriginal health. CMAJ 1996;155(11):1569-78.

12. Bill R, Shari B. Exploring the health and well being of gay, lesbian, bisexual and two-spirit people in Canada. Montreal, Quebec: McGill Centre for Applied Family Studies; 2000.

13. Ryan C, Huebner D, Diaz RM, Sanchez J. Family rejection as a predictor of negative health outcomes in white and Latino lesbian, gay, and bisexual young adults. Pediatrics 2009;123(1):346-52.

14. Calgary Immigrant Aid Society. Building bridges: Healthy living for Calgary's diverse community. Calgary, AB: Author; 2000.
15. Breakey WR, Fischer PJ, Kramer M, Nestadt G, Romanoski AJ, Ross A, et al. Health and mental health problems of homeless men and women in Baltimore. JAMA 1989;262(10):1352-7.

16. Hwang SW, Aubry T, Palepu A, Farrell S, Nisenbaum R, Hubley AM, et al. The health and housing in transition study: a longitudinal study of the health of homeless and vulnerably housed adults in three Canadian cities. Int J Public Health 2011;56(6):609-23.

17. Enard KR, Ganelin DM. Reducing preventable emergency department utilization and costs by using community health workers as patient navigators. J Healthc Manag 2013;58(6):412-27; discussion 28.

18. Kangovi S, Barg FK, Carter T, Long JA, Shannon R, Grande D. Understanding why patients of low socioeconomic status prefer hospitals over ambulatory care. Health Aff (Millwood). 2013;32(7):1196-203.

19. Levy BD, O’Connell JJ. Health care for homeless persons. N Engl J Med 2004;350(23):2329-32.

20. Keogh C, O’Brien KK, Hoban A, O'Carroll A, Fahey T. Health and use of health services of people who are homeless and at risk of homelessness who receive free primary health care in Dublin. BMC Health Serv Res 2015;15:58.

21. Hwang SW. Homelessness and health. CMAJ 2001;164(2):229-33.

22. First Nations Information GovernanceCentre. FIRST NATIONS REGIONALHEALTH SURVEY (RHS) 2008-2010 2012. Available at: www. fnigc.ca.

23. Royal College of Physicians and Surgegons, Canada. Royal College of Physician and Surgeons of Canada Objectives of Training in the Specialty of Internal Medicine 2011. 2011. Available at: http://www.royalcollege.ca/cs/ groups/public/documents/document/mdaw/mdg4/ edisp/088402.pdf.

24. McGarry KA, Clarke JG, Landau C, Cyr MG. Caring for vulnerable populations: curricula in U.S. internal medicine residencies. J Homosex 2008;54(3):225-32.

25. Higashi RT, Tillack A, Steinman MA, Johnston CB, Harper GM. The 'worthy' patient: rethinking the 'hidden curriculum' in medical education. Anthropol Med 2013;20(1):13-23.

26. Alpern JD, Davey CS, Song J. Perceived barriers to success for resident physicians interested in immigrant and refugee health. BMC Med Educ 2016;16:178.

27. Crandall SJ, Reboussin BA, Michielutte R, Anthony JE, Naughton MJ. Medical students' attitudes toward underserved patients: a longitudinal comparison of problem-based and traditional medical curricula. Adv Health Sci Educ Theory Pract 2007;12(1):71-86.

28. Wayne S, Dellmore D, Serna L, Jerabek R, Timm C, Kalishman S. The association between intolerance of ambiguity and decline in medical students' attitudes toward the underserved. Acad Med 2011;86(7):877-82.

29. Masson N, Lester H. The attitudes of medical students towards homeless people: does medical school make a difference? Med Educ 2003;37(10):869-72.

30. Pincavage AT, Razi RR, Arora VM, Oyler J, Woodruff JN. Resident education in free clinics: an internal medicine continuity clinic experience. J Grad Med Educ 2013;5(2):327-31.

31. Fancher TL, Keenan C, Meltvedt C, Stocker T, Harris T, Morfín J, et al. An academic-community partnership to improve care for the underserved. Acad Med 2011;86(2):252-8.

32. Meili R, Fuller D, Lydiate J. Teaching social accountability by making the links: qualitative evaluation of student experiences in a service-learning project. Med Teach 2011;33(8):659-66.

33. Sharma M. Developing an integrated curriculum on the health of marginalized populations: successes, challenges, and next steps. J Health Care Poor Underserved 2014;25(2):663-9.

34. Hasnain M, Massengale L, Dykens A, Figueroa E. Health disparities training in residency programs in the United States. Fam Med 2014;46(3):186-91.

35. Fornari A, Anderson M, Simon S, Korin E, Swiderski D, Strelnick AH. Learning social medicine in the Bronx: an orientation for primary care residents. Teach Learn Med 2011;23(1):85-9. 
36. Morris CG, Johnson B, Kim S, Chen F. Training family physicians in community health centers: a health workforce solution. Fam Med 2008;40(4):271-6.

37. Morris CG, Chen FM. Training residents in community health centers: facilitators and barriers. Ann Fam Med 2009;7(6):488-94.

38. Rabinowitz HK. Recruitment, retention, and follow-up of graduates of a program to increase the number of family physicians in rural and underserved areas. N Engl J Med 1993;328(13):934-9.

39. Rabinowitz HK, Diamond JJ, Markham FW, Hazelwood CE. A program to increase the number of family physicians in rural and underserved areas: impact after 22 years. JAMA 1999;281(3):255-60.

40. Au H, Harrison M, Ahmet A, Orsino A, Beck CE, Tallett S, et al. Residents as health advocates: The development, implementation and evaluation of a child advocacy initiative at the University of Toronto (Toronto, Ontario). Paediatr Child Health 2007;12(7):567-72.
41. Kuo AA, Shetgiri R, Guerrero AD, Barreto PM, Perez VH, Fond K, et al. A public health approach to pediatric residency education: responding to social determinants of health. J Grad Med Educ 2011;3(2):217-23.

42. Kaczorowski J, Aligne CA, Halterman JS, Allan MJ, Aten MJ, Shipley LJ. A block rotation in community health and child advocacy: improved competency of pediatric residency graduates. Ambul Pediatr. 2004;4(4):283-8.

43. van den Heuvel M, Au H, Levin L, Bernstein S, Ford-Jones E, Martimianakis MA. Evaluation of a social pediatrics elective: transforming students' perspective through reflection. Clin Pediatr (Phila) 2014;53(6):549-55.

44. Frye AW, Hemmer PA. Program evaluation models and related theories: AMEE guide no. 67. Med Teach 2012;34(5):e288-99. 